\title{
Characterization of a Transthyretin (Prealbumin) Variant Associated with Familial Amyloidotic Polyneuropathy Type II (Indiana/Swiss)
}

\author{
Francis E. Dwulet and Merrill D. Benson \\ Departments of Medicine and Biochemistry, Rheumatology Division, Indiana University Medical School, and Rheumatology Section, \\ Richard L. Roudebush Veterans Administration Medical Center, Indianapolis, Indiana 46202
}

\begin{abstract}
Amyloid fibrils were isolated from cardiac tissue of two brothers who died from familial amyloidotic polyneuropathy (FAP) type II. Sequence analysis on peptides derived from proteolytic cleavage with trypsin and fragmentation with cyanogen bromide reveal that the fibril subunit protein is derived from plasma transthyretin (prealbumin). About two-thirds of the fibril subunit protein was found to contain an amino acid substitution at position 84 where the normal isoleucine residue has been replaced by serine. Sequence analysis of the plasma transthyretin (prealbumin) from the two brothers as well as two clinically diagnosed FAP type II family members and two of four children of affected individuals showed the presence of serine at position 84. The presence of this substitution also correlates with low serum levels of retinolbinding protein and thus transthyretin (prealbumin) position 84 may be involved with the interaction of these two proteins.
\end{abstract}

\section{Introduction}

In 1956 Rukavina et al. (1) reported a large kindred of Swiss descent with hereditary amyloidosis who had settled in northeastern Indiana. At the time the clinical features of this malady were distinctive from the familial amyloidotic polyneuropathy (FAP $^{1}$ in Portuguese families that was described by Andrade (2). The Indiana/Swiss type of amyloidosis was characterized by early onset of the carpal tunnel syndrome followed by a more generalized peripheral neuropathy, blindness from vitreous deposits of amyloid, and cardiomyopathy. Unlike the Portuguese FAP, clinically significant renal involvement was absent. While a number of other kindreds with amyloidosis have been described in the last 30 years (Japanese, Swedish, Danish, Iowa, German, French) (3-8), the Indiana/Swiss syndrome has remained clinically distinct. Only the Maryland kindred described by Mahloudji, which also has a high incidence of carpal tunnel syndrome, clinically resembles the Indiana syndrome (7).

With the discovery that amyloid fibrils in the autosomal dominant amyloidoses were composed of transthyretin (prealbumin), it became obvious that these amyloidoses might be clas-

Address correspondence and reprint requests to Dr. Benson, Chief, Rheumatology Section, Richard L. Roudebush Veterans Administration Medical Center, 1481 W. 10th St., Indianapolis, IN 46202. 1986.

Received for publication 1 December 1985 and in revised form 2 June

1. Abbreviations used in this paper: FAP, familial amyloidotic polyneuropathy; HPLC, high performance liquid chromatography; PAGE, polyacrylamide gel electrophoresis; RBP, retinol-binding protein.

J. Clin. Invest.

(c) The American Society for Clinical Investigation, Inc.

0021-9738/86/10/0880/07 \$1.00

Volume 78, October 1986, 880-886 sified chemically (9). Pras et al. described a variant transthyretin (prealbumin) from the amyloid of a Jewish patient (10) and it is now known that at least one Swedish kindred $(11,12)$, two Japanese kindreds $(13,14)$, and the Portuguese patients with amyloidosis (15) all have a variant transthyretin (prealbumin) with a methionine substitution for valine at position 30 of the 127 amino acid residue transthyretin (prealbumin) molecule.

Recently we found that affected individuals in the Indiana/ Swiss kindred have low serum levels of retinol-binding protein (RBP), whereas other kindreds do not (16). Since RBP binds to transthyretin (prealbumin) in the plasma, this led us to postulate that another transthyretin (prealbumin) variant is present in this condition. To investigate this we have isolated and structurally characterized the amyloid protein of the Indiana/Swiss type.

\section{Methods}

Amyloid-laden tissue was obtained postmortem from two brothers who died of cardiac insufficiency and who had been diagnosed as having FAP type II. Amyloid fibrils were isolated from $30-\mathrm{g}$ samples of heart tissue by the procedure of Pras et al. (17). The fibril subunit protein was then isolated from fibril concentrates by denaturation, reduction, alkylation, and size exclusion chromatography as previously described (12). The subunit protein $(4 \mathrm{mg})$ was digested with trypsin and the peptides separated by reverse-phase high performance liquid chromatography (HPLC) on a column $(1 \times 25 \mathrm{~cm})$ of Synchrom RP-8 resin. When necessary, peptides were repurified on Altex Ultrasphere C-18 or Waters bondapakphenyl columns. Polyacrylamide gel electrophoresis (PAGE) was done as previously described (11).

The amyloid subunit protein and plasma transthyretin (prealbumin) were cleaved with cyanogen bromide as reported previously (18). To 2 $\mathrm{mg}$ of amyloid subunit protein was added $0.5 \mathrm{ml}$ of deoxygenated $70 \%$ formic acid and $2 \mathrm{mg}$ of cyanogen bromide. The mixture was stirred in the dark at room temperature for $24 \mathrm{~h}$ and then dried under vacuum. The peptides were dissolved in $0.5 \mathrm{ml}$ of $50 \%$ acetic acid and separated by reverse-phase high pressure liquid chromatography on a column (1 $\times 25 \mathrm{~cm})$ of Synchrom RP-P resin using a 2-propanol gradient $(0-56 \%$ during $90 \mathrm{~min}$ ) to elute the peptides.

All protein and peptide samples were degraded in an $890 \mathrm{C}$ liquidphase sequenator (Beckman Instruments, Inc., Fullerton, CA) using the $0.1 \mathrm{M}$ Quadrol buffer program. $3 \mathrm{mg}$ of polybrene was added to each sample to reduce extractive losses. Amino acid analyses were performed on a $119 \mathrm{C}$ instrument (Beckman Instruments, Inc.). All samples were hydrolyzed under vacuum for $24 \mathrm{~h}$ at $115^{\circ} \mathrm{C}$ using $5.7 \mathrm{~N}$ double-distilled $\mathrm{HCl}$ that contained $2 \mathrm{mg}$ of phenol to reduce oxidation.

Plasma transthyretin (prealbumin) was isolated using a three-step procedure involving DEAE Sephadex ion exchange chromatography, Affigel Blue dye ligand affinity chromatography, and size exclusion chromatography as has been reported previously (18). After denaturation in $70 \%$ formic acid the protein was digested with trypsin and the peptides separated by reverse-phase HPLC as for the amyloid subunit protein (19).

\section{Results}

Congo red staining of autopsy material from the two brothers revealed major amyloid deposits in their cardiac tissue. Both 
individuals had enlarged hearts that weighed 900 and $750 \mathrm{~g}$, respectively. From $30 \mathrm{~g}$ of starting tissue both samples yielded $\sim 100 \mathrm{mg}$ of water extract protein and $2 \mathrm{~g}$ of top layer protein. Both fractions were highly enriched for amyloid fibrils as demonstrated by Congo red staining. After denaturation, reduction, and alkylation, the fibril subunit protein was isolated by size exclusion chromatography (Fig. 1). On sodium dodecyl sulfate (SDS)-PAGE, peak IV was found to have molecular mass of $\sim 14,000 \mathrm{D}$ and to be size homogeneous. Reverse-phase HPLC also revealed a single major protein peak. The other fractions were found to be heterogeneous by the above criteria. From 200 $\mathrm{mg}$ of starting fibril material $\sim 14 \mathrm{mg}$ of peak IV was isolated, and it accounted for $\sim 20 \%$ of the solubilized isolated proteins.

Sequence analysis of peak IV material revealed a heterogeneous structure from which the parent molecule could not easily be identified. The cyanogen bromide fragmented material gave an HPLC profile that was indiscernible from non-FAP type I transthyretins (prealbumins). Sequence analysis of the major cyanogen bromide peptide provided a sequence that was identical to that from positions 14-52 of normal plasma transthyretin (prealbumin). Tryptic digestion of peak IV material generated a peptide mixture that gave the reverse-phase HPLC profile seen in Fig. 2. In general, peptides were isolated in $90 \%$ or greater purity. Amino acid composition and sequence analysis revealed that these peptides were derived from plasma transthyretin (prealbumin): the only primary structure difference was that peptide T10 (residues 81-103) was found to have a serine instead of the normal isoleucine at position 84 (Table I). The amino terminal peptide started predominately from transthyretin (prealbumin) position 5, but longer and shorter peptides were also present. Finally, for a preparation from one of the brothers, peptide 7-8 (residues 49-76) appeared to have both a glycine and the normal threonine at position 49 . The two small peaks after peptides $10^{\prime}$ and 10 had amino acid compositions and sequence analysis consistent with their being derived from $10^{\prime}$ and 10 with arginine 104 attached to the carboxyl terminal. Se-

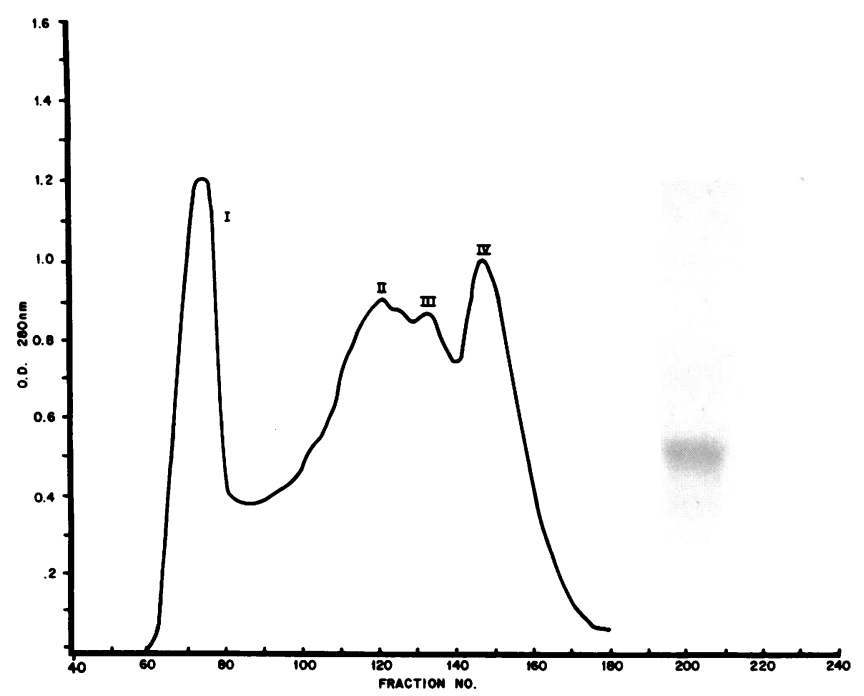

Figure 1. Gel permeation chromatography of FAP type II amyloid subunit protein on a column $(2.6 \times 85 \mathrm{~cm})$ of Sepharose CL6B. The buffer was $4.0 \mathrm{M}$ guanidine hydrochloride, $0.05 \mathrm{M}$ Tris $\mathrm{HCl}$, pH 8.2, the flow rate was $30 \mathrm{ml} / \mathrm{h}$, and the fraction size was $3.5 \mathrm{ml}$. The inset shows a $10 \%$ PAGE gel of peak IV. The single band migrated with the same mobility as isolated transthyretin (prealbumin).

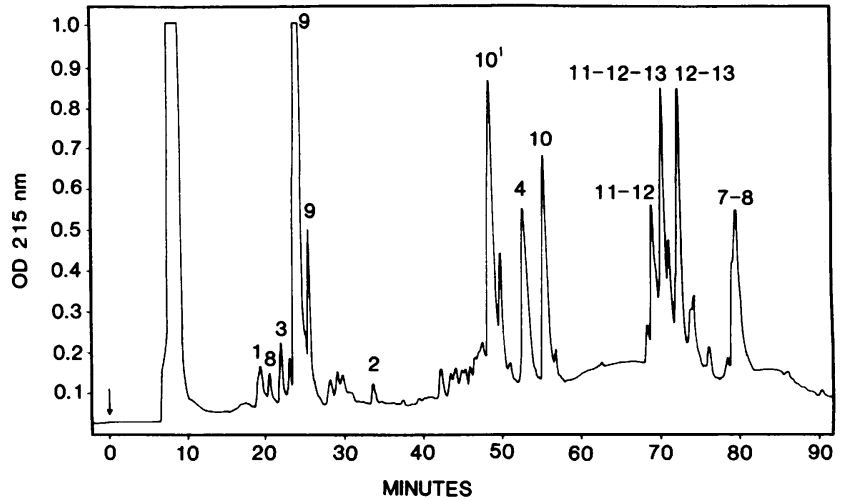

Figure 2. Reverse-phase HPLC separation of peptides formed by tryptic digestion of $4 \mathrm{mg}$ of amyloid subunit protein peak IV on a column $(1 \times 25 \mathrm{~cm})$ of Synchrom RP-8 resin. The column was equilibrated in $0.1 \%$ trifluoroacetic acid and the peptides eluted with a linear gradient from 0 to $35 \%$ acetonitrile generated over $75 \mathrm{~min}$. The flow rate was 2 $\mathrm{ml} / \mathrm{min}$ and the column was maintained at room temperature. Peaks are numbered to correspond to the tryptic peptides as noted in Fig. 3.

quenator yield data for all major peptides are shown in Table II while the alignment of all peptides are shown in Fig. 3.

Tryptic peptide HPLC maps for FAP type II and normal plasma transthyretin (prealbumin) can be seen in Fig. 4. These profiles are identical except that the FAP type II protein has peak $10^{\prime}$. By sequence analysis this peak contains residues $81-$ 103 of the transthyretin (prealbumin) molecule with a replacement at position 84 of a serine for the normal isoleucine.

\section{Discussion}

While large amounts of amyloid fibrils were isolated from the cardiac tissue, there was a low recovery of fibrils in the water supernatant, which is comparable with that seen for FAP type I tissue samples (11). To obtain the best yields of the subunit protein, solubilization in $8 \mathrm{M}$ guanidine required $48-72 \mathrm{~h}$ to dissociate the fibril subunit proteins from the matrix proteins. Sequence analysis of peak IV material revealed a multiple sequence. Review of these data after further studies on the tryptic peptides revealed that this fraction was composed of transthyretin (prealbumin) and that $\sim 40 \%$ of the material being sequenced started at position 5 of the transthyretin (prealbumin) molecule with an additional 20-30\% starting at positions 4 and 6.

The cyanogen bromide digest was done on two samples of the amyloid subunit protein. The first cleavage was performed using subunit protein obtained from the top-layer material. Sequence analysis of the major cyanogen bromide polypeptide gave the same amino acid residues as the starting material, which indicates that little or no cleavage had occurred. However, when the cyanogen bromide digest was performed on the subunit protein isolated from the water wash material, the major peptide isolated by HPLC gave a single sequence starting at position 14 of the transthyretin (prealbumin) molecule. This sequence was extended to position 52 with no differences from normal transthyretin (prealbumin) (Table II).

The tryptic digest of the subunit protein from one of the brothers gave the profile seen in Fig. 2 . There are only a few differences in this profile from that of normal transthyretin (prealbumin). First, the amino terminal peptide (T1) in the sub- 


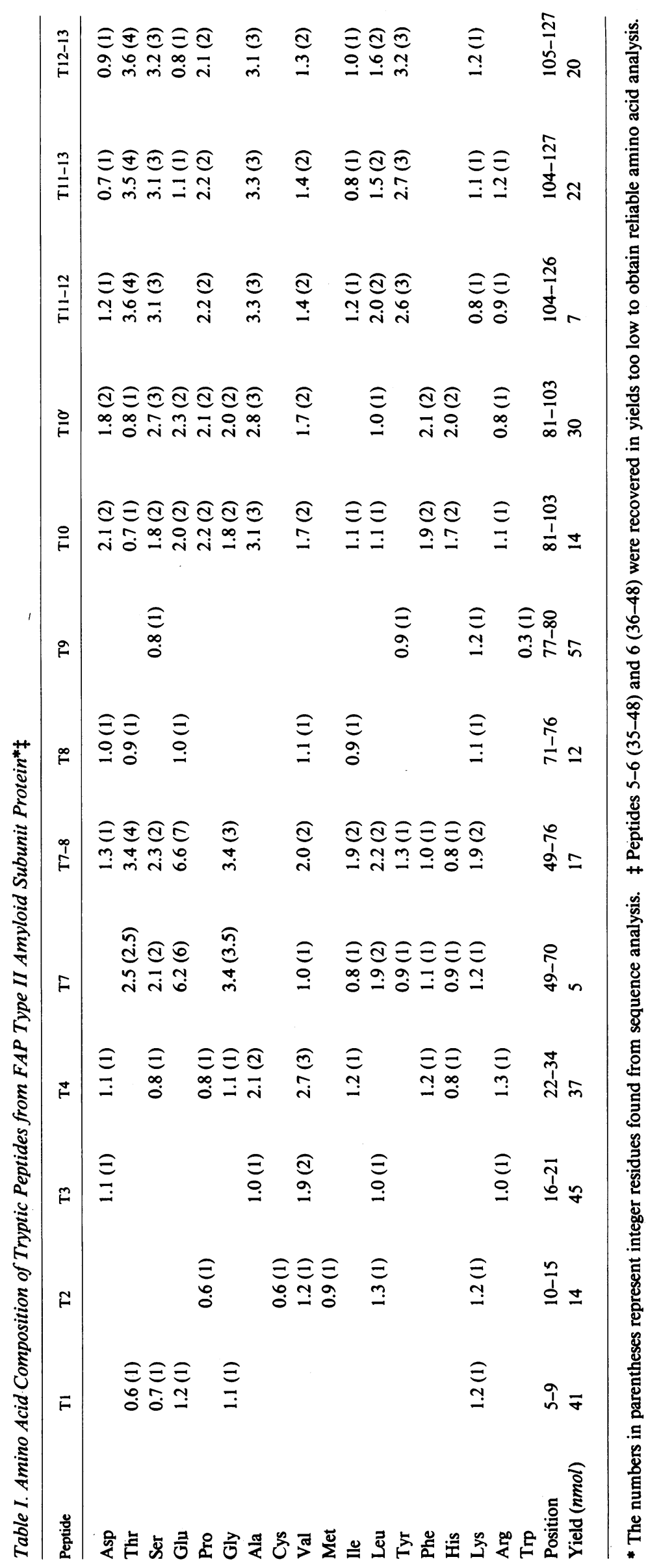




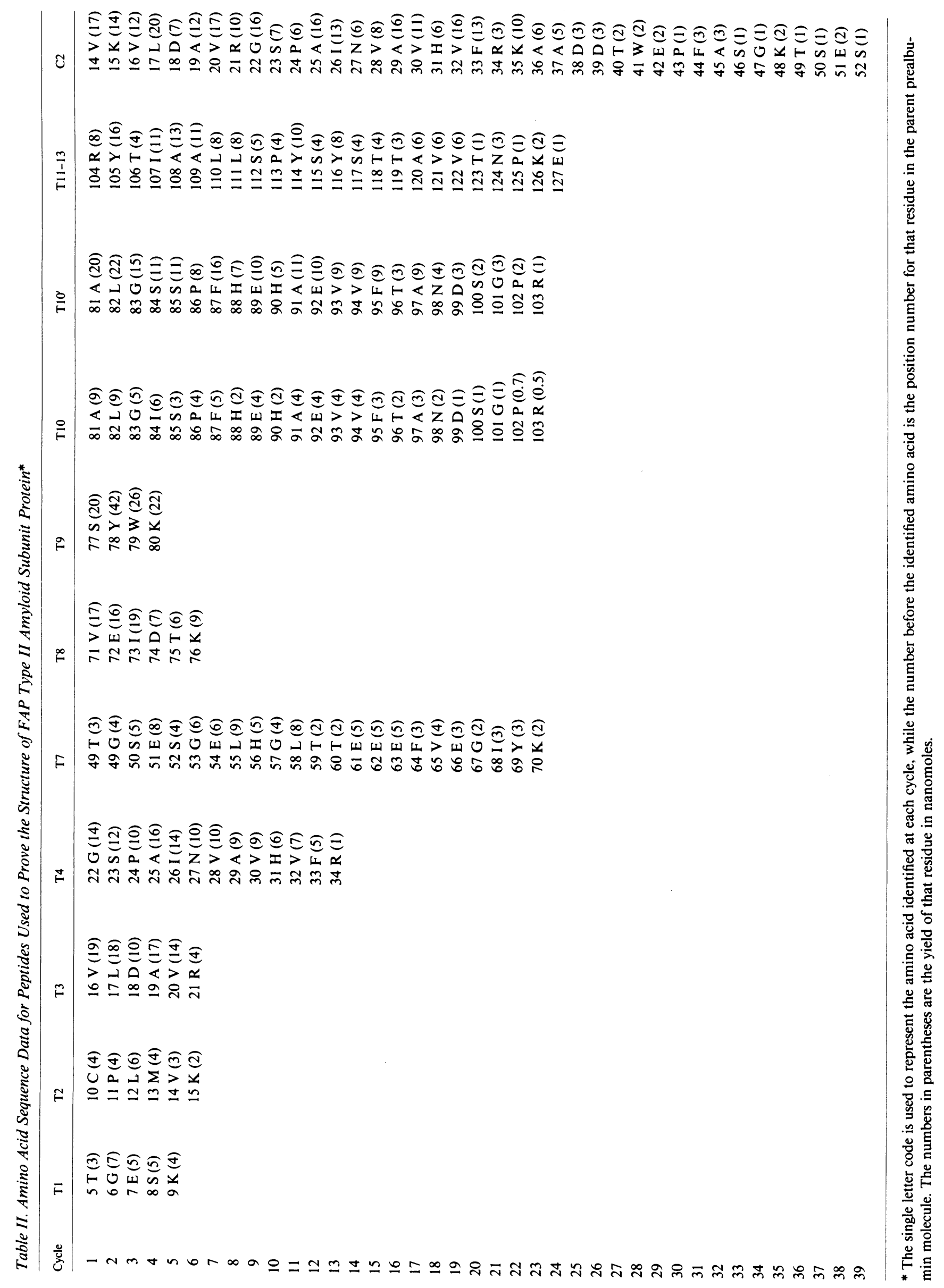




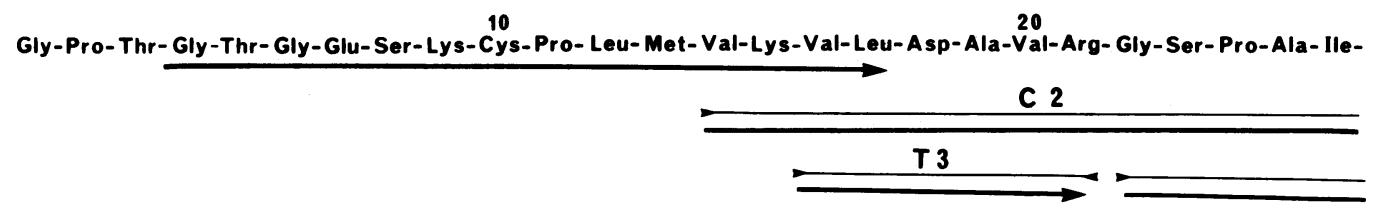

60

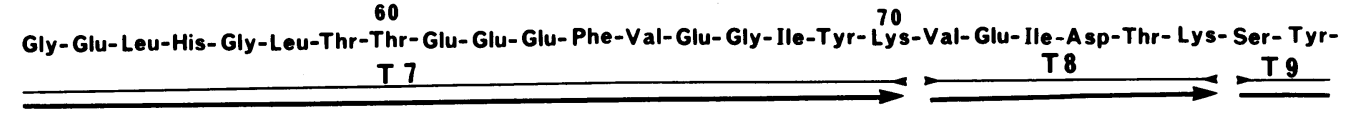

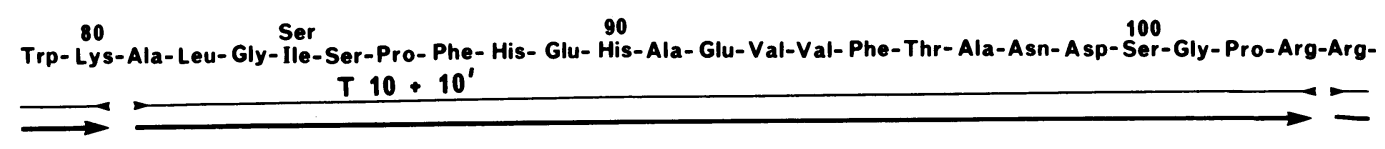

Tyr-Thr-Ile-Ala-Ala-Leu-Leu-Ser-Pro-Tyr-Ser-Tyr-Ser-Thr-Thr-Ala-Val-Val-Thr-Asn- Pro-Lys-Glu
T $11-12-13$
Figure 3. The complete amino acid sequence of the isolated amyloid subunit protein and the peptides used to determine the structure. Peptides labeled with a $\mathrm{C}$ were isolated after fragmentation with cyanogen bromide while those labeled with a $T$ were isolated after trypsin digestion. All peptides are numbered sequentially from the amino terminus. The sequence information obtained from each peptide is represented by an arrow under the appropriate sequence. unit protein elutes slightly earlier and is broader. This is most likely due to the facts that it is truncated and has a heterogeneous amino terminal. Second, peptide T2 (residues 10-15) was isolated in poor yields with limited recovery of carboxymethyl cysteine and methionine on amino acid analysis. Also, peptides T5-6 (residues 35-48) and T6 (residues 36-48) were isolated in very low yields (the small unlabeled peaks at 42 and 45 min, Fig. 2) and of insufficient purity for reliable sequence analysis. These findings are consistent with the cysteine 10 , methionine 13 , and tryptophane 41 all being partially or completely oxidized in the fibrils. That the subunit protein from top-layer fibril material did not show significant cleavage with cyanogen bromide is also consistent with oxidation of the methionine 13 . This is in contrast to FAP type I fibrils, which show no such oxidation. This difference may be due to the tissue in which the fibrils are deposited. In most FAP type I preparations the fibrils are isolated from kidney, while in FAP type II the fibrils are isolated from the heart. Since the heart is a very oxygen-rich organ it is possible that long-term exposure to these levels of oxygen leads to oxidation of these sensitive residues. Coupled to this it can be proposed that those fibrils found in the water wash are more recently formed and have not yet been oxidized or tightly entangled in the cellular matrix.

The peptide for residues 81-103 was found in two peaks (T10 and T10'). Peptide T10 had the normal sequence while peptide $\mathrm{T} 10^{\prime}$ had the same sequence but at position 84 the normal isoleucine had been replaced by a serine. Lastly, in one of the samples the peak for peptide T7-8 (residues 49-76) had a clearly observable shoulder, and on compositional analysis showed an extra half-residue of glycine. Upon sequence analysis both glycine and threonine were seen at the amino terminus of this peptide (position 49), while all other residues were the same as normal. If this were a real amino acid replacement it would represent a double substitution. This is of interest because it was initially reported that a Jewish hereditary amyloid also had a glycine at position 49 (10). Sequence analysis of amyloid subunit protein from the second brother with FAP type II revealed no glycine at position 49 . This, coupled to the fact that the cyanogen bromide sequence data only showed threonine at position 49 , has led us to believe that the glycine is not part of the polypeptide backbone but instead is the result of a chemical linkage of a residue of glycine to an amino acid side chain (probably serine, threonine, or lysine).

In an attempt to confirm if the glycine residue is part of the primary structure or is attached to the prealbumin molecule either before or after its incorporation into the fibrils, we isolated transthyretin (prealbumin) from the plasma of the two deceased brothers, two clinically proven affected family members, and four children of clinically affected individuals as well as of normal individuals. For all individuals the yield of isolated transthyretin (prealbumin) was $35-45 \%$ of theoretical, which is the range we have seen for this method (18). Because of the high stability of transthyretin (prealbumin) it is necessary to denature the protein before trypsin digestion. For these proteins we used the method of Nakazato et al. with incubation in $70 \%$ formic acid at room temperature for $18 \mathrm{~h}$ (19). We found this method acceptable, but only $20-40 \%$ of the molecules were fragmented with trypsin in this manner. To ascertain that neither the normal or variant protein was preferentially cleaved by trypsin, the undigested proteins from preparations of two affected individuals were redigested with trypsin. HPLC peptide profiles of these materials showed essentially complete cleavage and did not differ significantly from the first trypsin-digested material. The pattern for the two deceased brothers and two affected family members is seen in Fig. $4 A$ while the pattern for normal transthyretin (prealbumin) is seen in Fig. $4 \mathrm{~B}$. For both profiles, the patterns are identical except in the affected individuals where peak T10 is observed. Sequence analysis reveals that this is peptide 81103 with a serine for isoleucine at position 84 . Sequence analysis of peptide 7 and 7-8 both show only threonine at position 49 for all individuals tested. Since peptides T2, T5-6, and T6 were isolated in good yields from the plasma transthyretin with no 

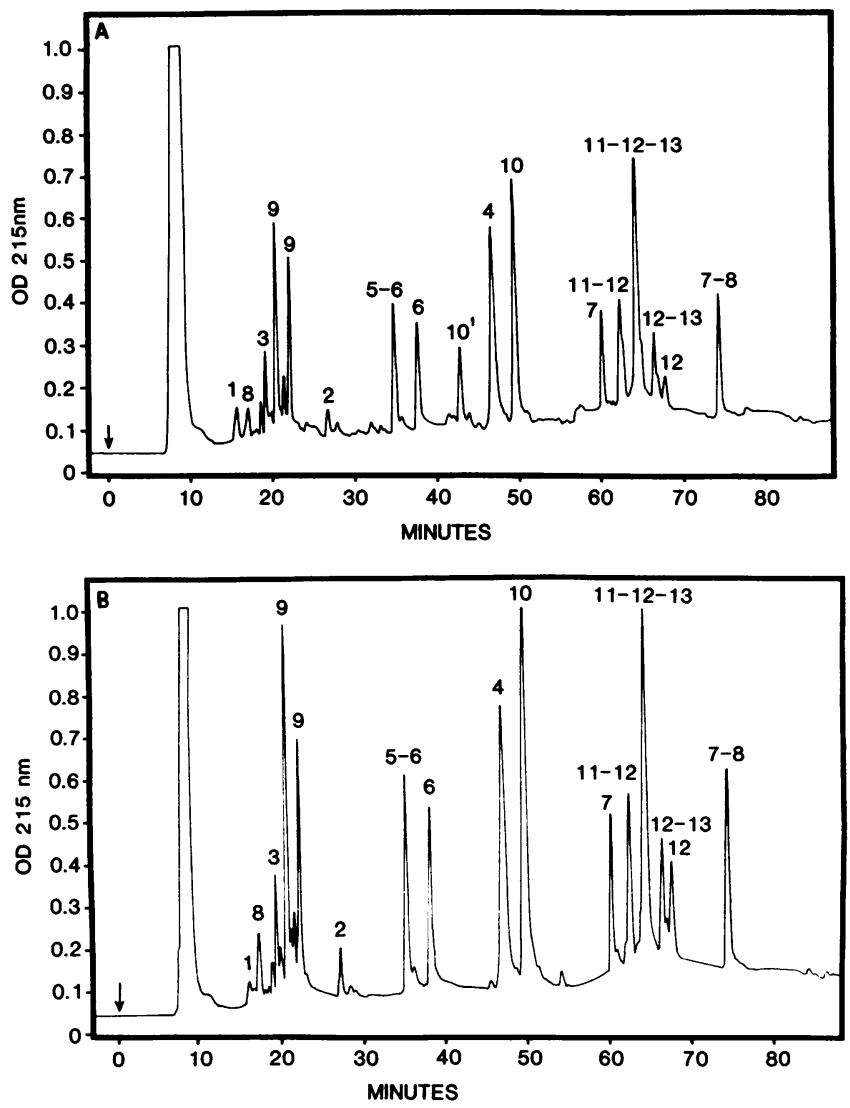

Figure 4. (A) Elution profile showing the separation of the peptides formed from trypsin digestion of plasma transthyretin (prealbumin) (3 $\mathrm{mg}$ ) from an individual with FAP type II. Separation was obtained on a Synchrom RP-8 column $(1 \times 25 \mathrm{~cm})$ using $0.1 \%$ TFA in water at a $2 \mathrm{ml} / \mathrm{min}$ flow rate as the initial buffer. A double gradient from 0 to $10 \%$ acetonitrile in $10 \mathrm{~min}$ followed by a gradient from 10 to $35 \%$ acetonitrile in $75 \mathrm{~min}$ was used to effect separation of the peptides. $(B)$ Separation of the peptides derived from a trypsin digestion of normal plasma transthyretin $(3 \mathrm{mg})$. Conditions were the same as above. All peaks are numbered as in Fig. 2. The two peaks labeled 9 gave identical composition and sequence analyses and may represent modification of the indole ring of $\operatorname{Trp} 79$.

loss of cysteine, methionine, and tryptophan, this is consistent with the loss of these residues in the fibril subunit protein being due to tissue oxidation.

From these studies it would seem that the glycine that appears to be at position 49 is not part of the primary structure and that it is not attached to transthyretin (prealbumin) in the plasma. It is possible that the residue is attached after the fibrils are deposited into the tissue and that this modification may be tissue specific. This would explain the presence of the adduct in some amyloid-laden tissues but not in others as has been reported in the amyloid of Jewish origin $(16,19)$.

For the four presymptomatic individuals whose transthyretin (prealbumin) were studied, two of them had peptide $\mathrm{T} 10^{\prime}$ and two did not. Prior studies show that affected individuals in this kindred have low RBP levels, which was true for the two presymptomatic individuals who had peptide T10. Therefore, it appears that the occurrence of low plasma RBP levels is associated with the position 84 substitution and may be used to identify carriers of the abnormal gene.

All the individuals with the gene coding for serine 84 showed a consistent serum pattern. In all the people with active amyloid deposition the variant transthyretin (prealbumin) accounted for $20-25 \%$ of the total plasma concentration. However, in individuals not exhibiting active disease the variant concentration was between 30 and $35 \%$ of the total serum transthyretin (prealbumin) level. This is consistent with what has been seen in FAP type I individuals and probably represents the enriched deposition of the variant protein in the amyloid fibrils with the resultant depletion of the plasma (12).

From the $x$-ray structure of the transthyretin (prealbumin) molecule it has been determined that position 84 is located on an external loop on the outer surface of the protein between beta sheet strands $E$ and $F(20)$. This position is on one of the most exposed segments of the molecule, and how this substitution leads to the formation of fibrils is uncertain. However, certain features would appear to be important. Position 84 is at the end of a short alpha helical region (positions 78-83) and a mutation from isoleucine to serine will have effects on hydrophobicity and hydrogen bonding. Since low ionic strength is known to dissociate transthyretin (prealbumin) and RBP, it would appear that hydrophobic interactions may play an important role in the association of these proteins (21). Thus, the replacement of isoleucine at position 84 with a serine would lead to a major reduction of hydrophobicity in this region and may lead to a higher dissociation constant for these proteins. This reduced affinity for RBP could explain the low serum levels of RBP because unbound to transthyretin (prealbumin) it is quickly cleared by the kidneys (22). How the serine at position 84 will alter the protein structure will have to await $x$-ray structure analysis of the variant protein.

From the genetic code and transthyretin (prealbumin) complementary DNA (cDNA) sequence it is clear that the change from isoleucine to serine involves a single base substitution where the second codon is changed from a uracil (thymine) to a guanine (23-25). This replacement of a purine for a pyrimidine base should alter the DNA so that specific nucleases will give different patterns for the normal and variant genes. Thus, it should be possible to identify carriers of this trait by differences in restriction nuclease patterns as has already been shown for the methionine for valine substitution in FAP type I individuals (26) and for alanine for threonine substitution in FAP Appalachian (27).

\section{Acknowledgments}

The authors wish to thank Marilyn Smith and Gretchen Bowker for technical assistance as well as Patricia Rusie and Karen Pickens for secretarial assistance.

This work was supported by Veterans Administration Medical Research (MRIS grant 583-0888) and by grants from the General Clinical Research Centers (National Institutes of Health) (RR-00750), the U. S. Public Health Service, National Institute of Arthritis, Diabetes, and Digestive and Kidney Diseases (AM-20582 and AM-7448), the Arthritis Foundation, the Grace M. Showalter Trust, and the Marion E. Jacobson Fund.

\section{References}

1. Rukavina, J. G., W. D. Block, C. E. Jackson, H. F. Falls, J. H. Carey, and A. C. Curtis. 1956. Primary systemic amyloidosis: a review and an experimental, genetic, and clinical study of 29 cases with particular emphasis on the familial form. Medicine. 35:239-344.

2. Andrade, C. 1952. A peculiar form of peripheral neuropathy. Familial atypical generalized amyloidosis with special involvement of the peripheral nerves. Brain. 75:408-427.

3. Araki, S., S. Mawatari, M. Ohta, A. Nakjima, and Y. Kuroiwa. 
1968. Polyneuritic amyloidosis in a Japanese family. Arch. Neurol. 18: 593-602.

4. Andersson, R. 1970. Hereditary amyloidosis with polyneuropathy. Acta Med. Scand. 188:85-94.

5. Frederiksen, T., H. Gotzsche, N. Harboe, W. Klaer, and K. Mellemgaard. 1962. Familial primary amyloidosis with severe amyloid heart disease. Am. J. Med. 33:328-335.

6. Van Allen, M. W., J. A. Frohlich, and J. R. Davis. 1969. Inherited predisposition to generalized amyloidosis. Neurology. 19:10-25.

7. Mahloudji, M., R. D. Teasdall, J. J. Adamkiewicz, W. H. Hartmann, P. A. Lambird, and V. A. McKusick. 1969. The genetic amyloidoses with particular reference to hereditary neuropathic amyloidosis, Type II (Indiana or Rukavina Type). Medicine. 48:1-37.

8. Julien, J., C. Vital, J. M. Vallat, A. Lagueny, and X. Ferrer. 1983. Neuropathies amyloides familiales dans trois families d'origine Francaise. Rev. Neurol. (Paris). 139:259-267.

9. Costa, P. P., A. S. Figueira, and F. R. Bravo. 1978. Amyloid fibril protein related to prealbumin in familial amyloidotic polyneuropathy. Proc. Natl. Acad. Sci. USA. 75:4499-4503.

10. Pras, M., E. C. Franklin, F. Prelli, and B. Frangione. 1981. A variant of prealbumin from amyloid fibrils in familial polyneuropathy of Jewish origin. J. Exp. Med. 154:989-993.

11. Benson, M. D. 1981. Partial amino acid sequence homology between an heredofamilial amyloid protein and human plasma prealbumin. J. Clin. Invest. 67:1035-1041.

12. Dwulet, F. E., and M. D. Benson. 1984. Primary structure of an amyloid prealbumin and its plasma precursor in a heredofamilial polyneuropathy of Swedish origin. Proc. Natl. Acad. Sci. USA. 81:694-698.

13. Tawara, S., M. Nakazato, K. Kangawa, H. Matsuo, and S. Araki. 1983. Identification of amyloid prealbumin variant in familial amyloidotic polyneuropathy (Japanese Type). Biochem. Biophys. Res. Commun. 116:880-888.

14. Kametani, F., H. Tonoike, A. Hoshi, T. Shinoda, and S. Kito. 1984. A variant prealbumin-related low molecular weight amyloid fibril protein in familial amyloid polyneuropathy of Japanese origin. Biochem. Biophys. Res. Commun. 125:622-628.

15. Saraiva, M. J. M., S. Birken, P. P. Costa, and D. S. Goodman. 1984. Amyloid fibril protein in familial amyloidotic polyneuropathy Portuguese type. J. Clin. Invest. 74:104-119.
16. Benson, M. D., and F. E. Dwulet. 1983. Prealbumin and retinol binding protein serum concentrations in the Indiana type hereditary amyloidosis. Arthritis Rheum. 26:1493-1498.

17. Pras, M., M. Schubert, D. Zucker-Franklin, A. Rimon, and E. C. Franklin. 1968. The characterization of soluble amyloid prepared in water. J. Clin. Invest. 47:924-933.

18. Dwulet, F. E., and M. D. Benson. 1983. Polymorphism of human plasma thyroxine binding prealbumin. Biochem. Biophys. Res. Commun. 114:657-662.

19. Nakazato, M., K. Kangawa, N. Minamino, S. Tawara, H. Matsuo, and S. Araki. 1984. Revised analysis of amino acid replacement in a prealbumin variant (SKO-III) associated with familial amyloidotic polyneuropathy of Jewish origin. Biochem. Biophys. Res. Commun. 123: 921-928.

20. Blake, C. C. F., M. J. Geisow, and S. J. Oatley. 1978. Structure of prealbumin: secondary, tertiary and quaternary interactions determined by Fourier refinement at 1.8A. J. Mol. Biol. 121:339-356.

21. Goodman, D. S. 1976. Retinol-binding protein, prealbumin and vitamin A transport. Prog. Clin. Biol. Res. 5:313-330.

22. Robbins, J., S. Cheng, M. C. Gershengorn, D. Glinoer, H. J. Cahnmann, and H. Edelnoch. 1978. Thyroxine transport proteins of plasma. Molecular properties and biosynthesis. Recent Prog. Horm. Res. 4:477-519.

23. Mita, S., S. Maeda, K. Shimada, and S. Araki. 1984. Cloning and sequence analysis of cDNA for human prealbumin. Biochem. Biophys. Res. Commun. 124:558-564.

24. Wallace, M. R., S. L. Naylor, B. Kluve-Beckerman, G. L. Long, L. McDonald, T. B. Shows, and M. D. Benson. 1985. Localization of the human prealbumin gene to chromosome 18. Biochem. Biophys. Res. Commun. 129:753-758.

25. Tsuzuki, T., S. Mita, S. Maeda, S. Araki, and K. Shimada. 1985. Structure of the human prealbumin gene. J. Biol. Chem. 260:224-227.

26. Sasaki, H., Y. Sakaki, H. Matsuo, I. Goto, Y. Kuroiwa, I. Sahashi, A. Takahashi, T. Shinoda, T. Isobe, and Y. Takagi. 1984. Diagnosis of familial amyloidotic polyneuropathy by recombinant DNA techniques. Biochem. Biophys. Res. Commun. 125:636-642.

27. Wallace, M. R., F. E. Dwulet, P. M. Conneally, and M. D. Benson. 1986. Biochemical and molecular genetic characteristic of a new variant prealbumin associated with hereditary amyloidosis. J. Clin. Invest. 78: 6-12. 